\title{
Dynamic balance of the aortomitral junction
}

\author{
Emmanuel Lansac, $\mathrm{MD}^{\mathrm{a}}$ \\ Khee Hiang Lim, MS ${ }^{\mathrm{a}}$ \\ Yu Shomura, MD ${ }^{\mathrm{a}}$ \\ Wolfgang A. Goetz, MD, PhD \\ Hou Sen Lim, MS ${ }^{\mathrm{a}}$ \\ Nolan T. Rice, $\mathrm{MS}^{\mathrm{b}}$ \\ Hashim Saber, $\mathrm{PhD}^{\mathrm{b}}$ \\ Carlos M. G. Duran, MD, PhD ${ }^{\mathrm{a}}$
}

From The International Heart Institute of Montana Foundation at St Patrick Hospital ${ }^{\mathrm{a}}$ and The University of Montana, ${ }^{\mathrm{b}}$ Missoula, Mont.

Read at the Eighty-first Annual Meeting of The American Association for Thoracic Surgery, San Diego, Calif, May 6-9, 2001.

Received for publication May 29, 2001; revisions requested July 27, 2001; revisions received Sept 19, 2001; accepted for publication Oct 16, 2001

Address for reprints: Carlos M. G. Duran, $\mathrm{MD}, \mathrm{PhD}$, The International Heart Institute of Montana, 554 West Broadway, Missoula, MT 59802 (E-mail: duran@ saintpatrick.org).

J Thorac Cardiovasc Surg 2002;123:911-8

Copyright $(\odot) 2002$ by The American Association for Thoracic Surgery

$0022-5223 / 2002 \$ 35.00+0 \quad \mathbf{1 2 / 6 / 1 2 1 2 8 6}$

doi: $10.1067 / \mathrm{mtc} .2002 .121286$
Objective: The aortic and mitral valves have been studied in isolation, as if their functions were independent. We hypothesized that both valves work in synchrony on the basis of the shared myocardial pump and orifice.

Methods: Six sonometric crystals (7 sheep) were placed in both trigones, the midpoint of the anterior and posterior anulus, and the lateral extremities of the posterior anulus. In a separate series of animals, 3 crystals ( 8 sheep) were implanted in the aortic annular base of the right, left, and noncoronary sinuses of Valsalva. In an acute, open-chest model, under stable hemodynamic conditions, geometric changes were time related to simultaneous left ventricular and aortic pressures.

Results: From mid-diastole to end-systole, the mitral anulus area contracted by $-16.1 \% \pm 1.9 \%$ (mean $\pm \mathrm{SEM}$ ), whereas the aortic base area expanded by $+29.8 \% \pm 3.3 \%$ during systole. The mitral anulus deformation was heterogeneous. In systole, the anterior mitral anulus expanded (intertrigonal distance, $+11.5 \% \pm$ $2.3 \%$ ) and the posterior mitral anulus contracted (distance between lateral extremities of the posterior anulus, $-12.1 \% \pm 1.5 \%$ ). The intertrigonal distance corresponded to the base of the left and noncoronary sinus of Valsalva, which expanded similarly during systole $(+12.9 \% \pm 2.0 \%)$. The anteroposterior diameter of the mitral anulus was reduced twice that of the transverse diameter. This disparity of reduction can be explained by the posterior displacement of the intertrigonal area corresponding to the systolic aortic root expansion.

Conclusions: Mitral anulus deformation is closely related to aortic root dynamics. During systole, the posterior movement of the aortic curtain allows for aortic root expansion, probably to maximize ejection, whereas during diastole, aortic root reduction participates in mitral anulus dilatation. These findings should affect mitral and aortic surgical approaches.

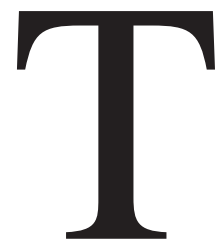

he aortic and mitral valves have been considered 2 separate entities and therefore studied in isolation, as if their functions were independent. The aortic valve can no longer be understood as consisting of 3 equal leaflets that passively follow the changes in blood flow. Recent studies have shown that it includes the 3 (unequal) leaflets, the sinuses of Valsalva, the sinotubular junction, the coronary orifices, and the left ventricular (LV) outflow tract. The aortic root is a dynamic structure that expands during systole to reduce shear stress on the aortic leaflets. ${ }^{1-6}$ The conformational changes of the mitral anulus during the cardiac cycle are known. ${ }^{7,8}$ Mitral anulus reduction has been traditionally related to its posterior contraction, whereas its anterior portion or intertrigonal distance remains fixed. ${ }^{7}$ 


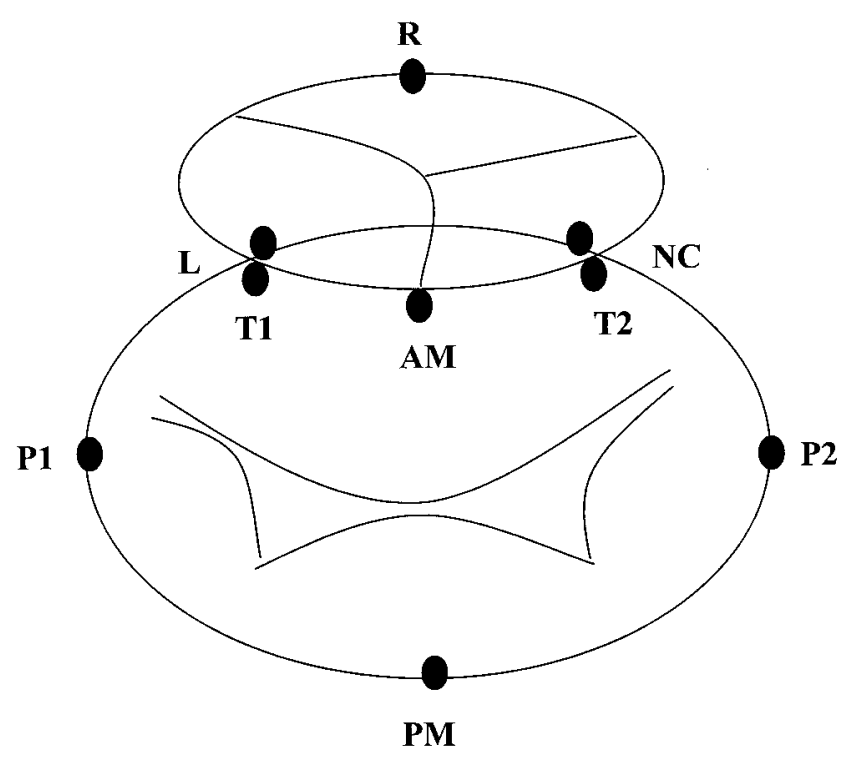

Figure 1. Location of the sonomicrometry crystals in the aortic root base and in the mitral anulus. $R, L$, and $N C$, Base of the right, left, and noncoronary sinuses of Valsalva; $T 1$ and $T 2$, left and right trigones; $A M$, midpoint between $\mathrm{T} 1$ and $T 2 ; P M$, midpoint of posterior anulus; $\boldsymbol{P 1}$ and $\boldsymbol{P}$, widest mitral diameter.

More recently, several authors ${ }^{9-12}$ have contested this intertrigonal immobility, although its underlying mechanism remains uncertain. Because the mitral and aortic valves share a common LV myocardial pump and orifice, we hypothesized that both valves not only work in synchrony but also must contribute to each other's geometric changes. In an attempt to elucidate this issue, the 3-dimensional sonometric changes of the aortic and mitral anuli were time related $(200 \mathrm{~Hz})$ with $\mathrm{LV}$ and aortic pressures during the normal cardiac cycle. ${ }^{13,14}$

\section{Materials and Methods}

The aortic and mitral anulus changes during the cardiac cycle were studied by means of digital 3-dimensional sonomicrometry (Sonometrics, London, Ontario, Canada). Eight adult sheep (43 $\pm 2 \mathrm{~kg}$, mean \pm SEM) underwent implantation of 3 ultrasonic crystals at the lowest point of each sinus of Valsalva, corresponding to the aortic root base. In a separate series of animals, 7 adult sheep $(68.7 \pm 8.8 \mathrm{~kg})$ underwent implantation of 6 ultrasonic crystals on the mitral anulus.

\section{Surgical Protocol}

Anesthesia was induced with intravenous ketamine $(1.0 \mathrm{mg} / \mathrm{kg})$ and propofol $(4.0 \mathrm{mg} / \mathrm{kg})$ and maintained with isoflurane $(1.5 \%$ $2.5 \%)$. Artificial ventilation was achieved with a volume-regulated respirator (North American Drager, Telford, Pa) supplemented with oxygen at $2 \mathrm{~L} / \mathrm{min}$. The heart was exposed by means of a standard left thoracotomy through the fourth intercostal space. The left femoral (16F) and left internal thoracic (10F) arteries were cannulated. A venous cannula was inserted into the right atrium
(32F). The aorta and arch vessel were crossclamped, and cold crystalloid cardioplegic solution was infused into the root. Onemillimeter ultrasonic crystals were implanted and secured with 5-0 polypropylene sutures (Figure 1). The anterior leaflet is identified with the letter "A," the posterior leaflet is identified with the letter "P," and those paired structures to the left or right of the surgeon are identified with the numerals 1 or $2 .{ }^{15}$ Through a left atriotomy, 6 crystals were placed on the mitral anulus: left and right trigones defining the intertrigonal distance (T1-T2); the midpoint of the anterior and posterior anulus defining the anteroposterior mitral diameter (AM-PM); and the left and right lateral extremities of the insertion of the posterior leaflet, defining the mitral transverse diameter (P1-P2). Through a transverse aortotomy, a crystal was placed at the lowest point of each of the right $(\mathrm{R})$, left $(\mathrm{L})$, and noncoronary (NC) sinuses of Valsalva corresponding to the aortic base of the aortic root. The crystals were oriented so that they pointed toward the lumen. The crystal's electrodes were exteriorized through the aortic wall at each point of insertion to reduce their possible interference with valve movements. The same surgeon placed all crystals to avoid interoperator variability. A highfidelity catheter-tipped pressure transducer (model 510; Millar Instruments, Houston, Tex) was placed in the proximal ascending aorta and through the apex in the LV cavity. A flow probe was placed on the ascending aorta (Transonic Flowmeter T206; Transonic Systems Inc, Ithaca, NY).

\section{Experimental Design}

After discontinuing cardiopulmonary bypass while the animal was still anesthetized with an open chest but hemodynamically stable (at least 15 minutes), recordings were taken at $200 \mathrm{~Hz}$ (200 data points per second). Epicardial 2-dimensional color Doppler echocardiography was used to assess valve competence. At the end of the experiment, the heart was arrested by means of lethal injection of potassium chloride and explanted, and the correct position of the crystals was checked. All animals received humane care in compliance with the principles of the Animal Welfare Act, the "Guide for Care and Use of Laboratory Animals" from the United States Department of Agriculture, and the Institutional Animal Care and Use Committee of the University of Montana.

\section{Definition of the Phases of the Cardiac Cycle}

In both groups of animals, the geometric changes were time related to each phase of the cardiac cycle defined from the aortic and LV pressure tracings. ${ }^{16,17}$ End-diastole or the beginning of systole and of the isovolumic phase was defined as the point of positive inflexion of the LV pressure tracing $(\mathrm{dP} / \mathrm{dt}>0)$. The end of isovolumic contraction was defined as the beginning of ejection at the crossing point of LV and aortic pressure tracings (gradient of aortic/LV pressure $=0$ ). The dicrotic notch in the aortic pressure curve defined the end of ejection. The end of isovolumic relaxation was defined as the lowest point of LV pressure tracing after ejection $(\mathrm{dP} / \mathrm{dt}=0) .^{5}$

\section{Definition of the Anatomic Regions}

The aortic annular base was studied at each time point of the cardiac cycle by determining its area calculated from the 3 basal crystals and the changes in the 3 basal lengths between crystals (NC-R, R-L, and L-NC). The mitral anulus was studied by deter- 
mining its area, 5 circumferential lengths (T1-T2, T2-P2, P2-PM, $\mathrm{PM}-\mathrm{P} 1$, and P1-T1), and 2 diameters (anteroposterior AM-PM and transverse P1-P2).

\section{Data Acquisition and Calculation of Annular Deformations}

Crystal displacements were measured with the Sonometrics Digital Ultrasonic Measurement System TRX Series 16 and 1-mm transmitter-receiver crystals. A postprocessing program (SonoSOFT Version 3.1.4, Sonometrics Corp) was used to examine each individual length tracing between crystals and for 3-dimensional reconstruction of the crystal coordinates. All crystal distances, pressures, flows, and electrocardiographs were synchronized and recorded at the same time line on the same screen with the Sonometrics system.

Length data were obtained directly from the measured distances between the pair of crystals, and Lagrangian strain ${ }^{18}$ was used to define the deformation from maximum to minimum values. The aortic root basal area was defined from the 3 corresponding crystals and calculated by using the Heron formula. ${ }^{19}$ The mitral anulus area was calculated from the 5 corresponding crystals that were broken into 3 triangles and calculated with the Heron formula. The aortic root diameter was calculated with the circumscribe formula.

Each length and area was defined by 2 percentages: (1) the total percentage of change with reference to minimum and maximum value and (2) the percentage change for each phase of the cardiac cycle relative to the total changes over the entire cardiac cycle.

\section{Measurements and Statistical Analysis}

Aortic and mitral anulus dynamic data were calculated separately. After close examination of the data, 3 consecutive heartbeats that contained the least amount of noise were chosen for analysis. The summary statistics are reported as means \pm 1 SEM. Univariate generalized linear model statistical methods were used to test for significant differences between each aortic base length expansion. Area and length changes of the aortic and mitral anulus within each group were tested for significance by using the Student $t$ test for paired observation. The time-related changes of the aortic base L-NC length and the mitral intertrigonal distance (T1-T2) during each phase of the cardiac cycle were compared by using standard linear regression analysis (the Pearson correlation). The sloperegression parameter was examined by using analysis of variance. All statistical analyses were done with the SPSS 0.9 program.

\section{Results}

\section{Model Characteristics}

At the time of recording, hemodynamic conditions were as follows for the aortic valve group: heart rate, $145 \pm 8$ beats/min; aortic pressure, 70/45 $\pm 5 / 4 \mathrm{~mm} \mathrm{Hg}$; stroke volume, $20 \pm 2 \mathrm{~mL}$; and cardiac output, $2.8 \pm 0.3 \mathrm{~L} / \mathrm{min}$. Hemodynamic conditions for the mitral valve group were as follows: heart rate, $99 \pm 6$ beats/min, aortic pressure, $67 / 40 \pm 2 / 3 \mathrm{~mm} \mathrm{Hg}$; stroke volume, $33 \pm 2 \mathrm{~mL}$; and cardiac output, $2.9 \pm 0.4 \mathrm{~L} / \mathrm{min}$. All valves were competent on epicardial echocardiography. At necropsy, all crystals were in the correct position in all animals.
Aortic Anulus Base Motion During the Cardiac Cycle From end-diastole to the first third of ejection, the basal area of the aortic root expanded by $+29.8 \% \pm 3.3 \%$, with $+50.7 \% \pm 4.5 \%$ of the expansion occurring before ejection (Figure 2 and Table 1). The aortic root basal diameter increased by $+10.6 \% \pm 0.3 \%$ from end-diastole $(20.7 \pm$ $0.4 \mathrm{~mm})$ to the first third of ejection $(22.9 \pm 0.3 \mathrm{~mm})$. The expansion of the aortic annular base was initiated during late diastole and increased dramatically during the isovolumic contraction until the first third of ejection, when it reached maximum expansion. Although the 3 basal lengths expanded during systole, their expansions were significantly different (generalized linear model, $P<.001$ ): R-L $(+19.2 \% \pm 2.0 \%)$ expanded more than L-NC $(+12.9 \% \pm$ $2.0 \%)$ and more than NC-R $(+8.4 \% \pm 0.8 \%)$. Therefore it was the myocardial septal portion of the aortic root base (R-L basal length) that expanded most during the cardiac cycle, whereas the aortomitral junction (L-NC basal length) increased by $+12.9 \% \pm 2.0 \%$.

\section{Mitral Anulus Motion During the Cardiac Cycle}

Maximal expansion of the mitral anulus area occurred during mid-diastole, and that of the minimal annular area occurred during the second half of ejection (Figure 3 ). From mid-diastole to the second half of ejection, the mitral anulus area contracted by $-16.1 \% \pm 1.9 \%$. Most of this contraction $(-70.0 \% \pm 6.8 \%)$ occurred before the beginning of isovolumic contraction (Table 1). During systole, the mitral anulus kept contracting with a complex deformation that included a brief re-expansion during the isovolumic contraction and another during the first third of ejection. The mitral anulus deformation was heterogeneous (Figure 4). Although the posterior part of the mitral anulus contracted mainly from early diastole to the beginning of systole, the anterior portion or intertrigonal distance expanded (T1-T2, $+11.5 \% \pm 2.3 \%$ ). This expansion occurred from late diastole to the first third of ejection (Table 2 and Figure 3). The anteroposterior mitral anulus diameter (AM-PM, $-23.6 \%$ $\pm 2.5 \%$ ) was reduced by about twice the transverse diameter $(\mathrm{P} 1-\mathrm{P} 2,-12.1 \% \pm 1.5 \%)$. The anteroposterior diameter was smallest when the intertrigonal distance reached its maximum expansion (Figure 3 ). The change in length between trigones was not due to the elasticity of this fibrous tissue but to continuous changes in its conformation. Its midportion (AM) moved back and forth toward the mitral orifice. During systole, the angle at AM between T1 and T2 decreased by $-9.1 \% \pm 0.8 \%$, showing the intertrigonal distance bulging toward the mitral orifice.

\section{Aortomitral Synchrony}

The aortic and mitral valves share the so-called aortic curtain. This fibrous tissue, anchored to the 2 trigones (T1 and $\mathrm{T} 2$ ), is situated immediately below the left and noncoronary 
aortic leaflets and is in continuity with the anterior leaflet of the mitral valve. We observed that the dynamics between the lowest point of the left and noncoronary sinuses (L-NC) were similar to the dynamics of the intertrigonal distance (T1-T2) and were strongly correlated $(r=0.85)$ at each phase of the cardiac cycle (regression-slope parameter, $P=$ .07). Maximal expansion was similar between both distances (T1-T2, $+11.5 \% \pm 2.3 \%$; basal L-NC length, $+12.9 \% \pm 2.0 \%$ ). Also, both distances increased from late diastole until the first third of ejection, when both lengths started to decrease during the rest of systole (Table 2). Therefore, it can be concluded that both the mitral intertrigonal distance and the aortic curtain are a common structure or mitroaortic junction. During late diastole and systole, the aortic base and the mitroaortic junction expanded while the remaining mitral anulus contracted. During early diastole, the mitral anulus expanded, whereas the mitroaortic junction was reduced (Figure 5). This is a very efficient mechanism to enhance LV filling and emptying.

\section{Discussion}

In spite of the well-known close anatomic proximity of the aortic and mitral valves, they have been considered, both functionally and surgically, as independent entities. Recently, 2 factors made us question this simplistic approach. First, interest in the pathophysiology of functional mitral disease has evidenced that this valve must be understood as an integral part of the left ventricle. Second, detailed studies of the complex functional anatomy of the aortic valve $e^{2-6}$ have shown the need to include the LV outflow tract in the equation. Sharing a common LV myocardial pump and orifice, we hypothesized that the aortic and mitral valves must work in synchrony. Correct function of one valve requires integrity of the other, and consequently, surgical interference with one must take into account its effect on the other.

Previous studies described the aortic valve complex (including the aortic root) as a dynamic structure, expanding before and during ejection as a mechanism to reduce shear stress on the leaflets and to maximize LV function. ${ }^{1-6}$ Furthermore, Van Renterghem and colleagues ${ }^{3}$ described a heterogeneous motion of the aortic annular base with the expansion of the aortomitral junction (L-NC basal length) while the remaining segments adjoining the myocardium were contracting. Very noisy signals, as well as data available for less than half of the animals, might explain the difference with our study, which confirmed the systolic expansion of the aortomitral junction but also showed the simultaneous expansion of the 2 other segments in significantly different proportions $(P<.001)$.

Mitral anulus motion has been also extensively described by using radiopaque markers, as well as 3-dimensional sonomicrometry. ${ }^{7,9,10,14,20}$ According to previous studies, maximum mitral anulus area is observed during early dias- 


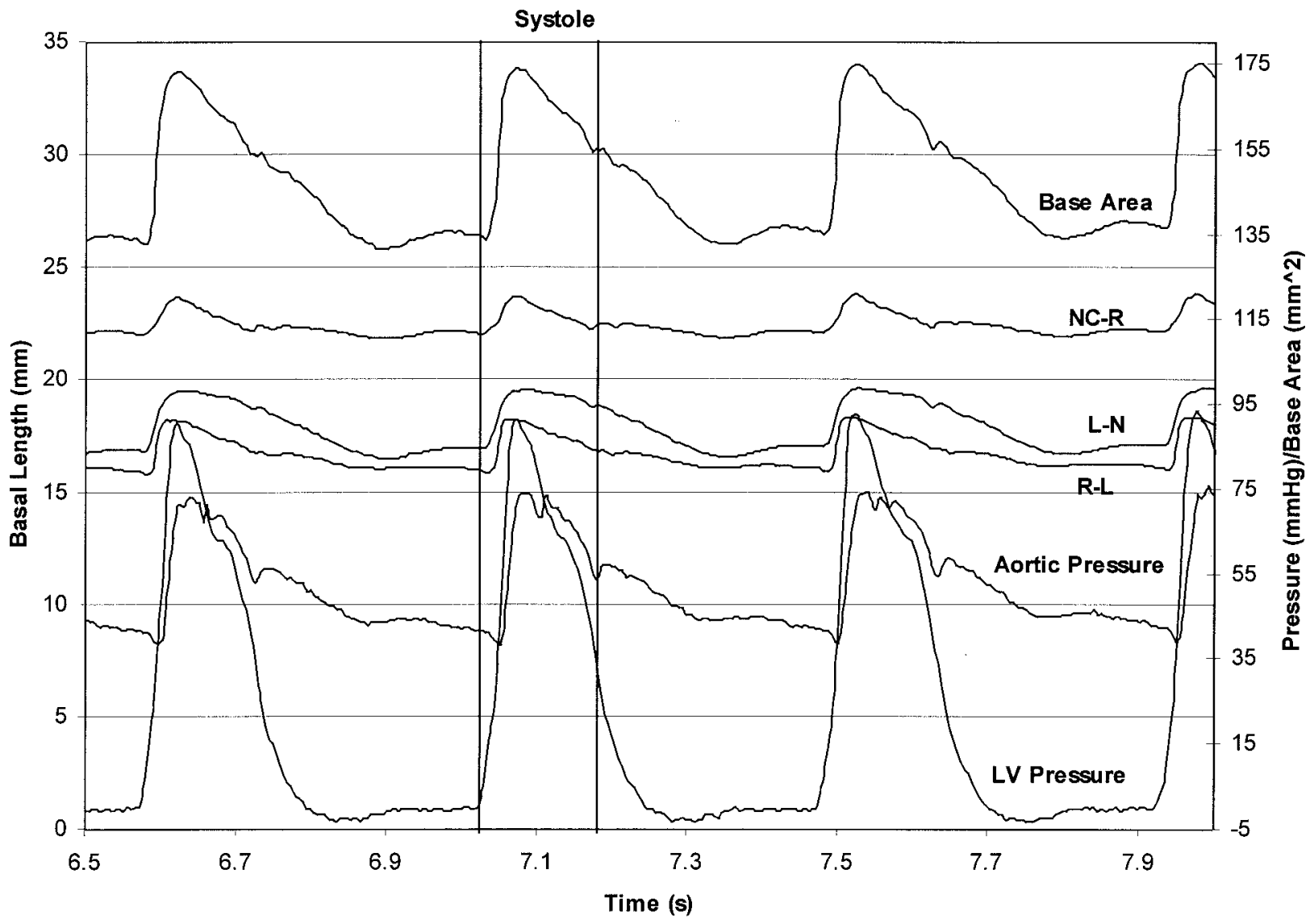

Figure 2. Dynamic changes of the aortic root base area during the cardiac cycle (Base area) and 3 basal lengths: noncoronary-right $(N C-R)$, left-noncoronary $(L-N)$, and right-left $(R-L)$ sinuses.

tole, with most of the annular size reduction occurring during the presystolic period. Proportion differences with other studies might be explained by the hemodynamic conditions, which are known to substantially affect the mitral anulus contraction. ${ }^{7}$ The anteroposterior anulus reduction found in our study (23\%) was more than double the $8 \%$ to $10 \%$ reported by Glasson and colleagues. ${ }^{9}$ In addition to a possible variability in marker location, the fact that Glasson and colleagues' animals were studied under $\beta$-blockade might explain this difference. More recently, interest has been focused on the heterogeneous mitral anulus motion, with an unexpected systolic expansion of the anterior portion..$^{9,10}$ Glasson and coworkers ${ }^{9}$ considered that the lengthening of the anterior mitral anulus was possibly related to a passive elongation of the fibrous tissue by the active contraction of the surrounding part of the anulus or LV myocardial fibers.

Although our data confirmed the systolic expansion of the anterior mitral anulus, we hypothesize a different mechanism. Anatomically, both valves are situated in the common orifice at the base of the left ventricle and are separated by the aortic curtain anchored to the 2 fibrous trigones.
Superiorly, the aortic curtain is part of the aortic root anulus, and inferiorly, it is in continuity with the anterior leaflet of the mitral valve..$^{21,22}$ In an attempt to analyze the functional relationships between the 2 valves, it was decided to study the time-related events in the aortic and mitral anuli. Ascending aortic and LV pressures were required to precisely define the different phases of the cardiac cycle and the percentage of the cyclic changes occurring in each experimental animal.

Analysis of the combined data from the aortic and mitral annular movements clearly showed their complementary synchronicity. The mitral anulus contracted by $-16 \%$ from mid-diastole to the second half of ejection. Seventy percent of this contraction occurred before the isovolumic phase related to the posterior mitral anulus contraction, whereas the expansion $(11.5 \% \pm 2.3 \%)$ of the anterior part of the anulus or intertrigonal distance was delayed from late diastole until the first third of ejection. In opposition to mitral orifice contraction, the aortic anulus expanded by about $30 \%$ from late diastole to the first third of ejection, with $50 \%$ of its expansion occurring during the isovolumic phase $(r=0.85)$. These changes are surprising given the fibrous 


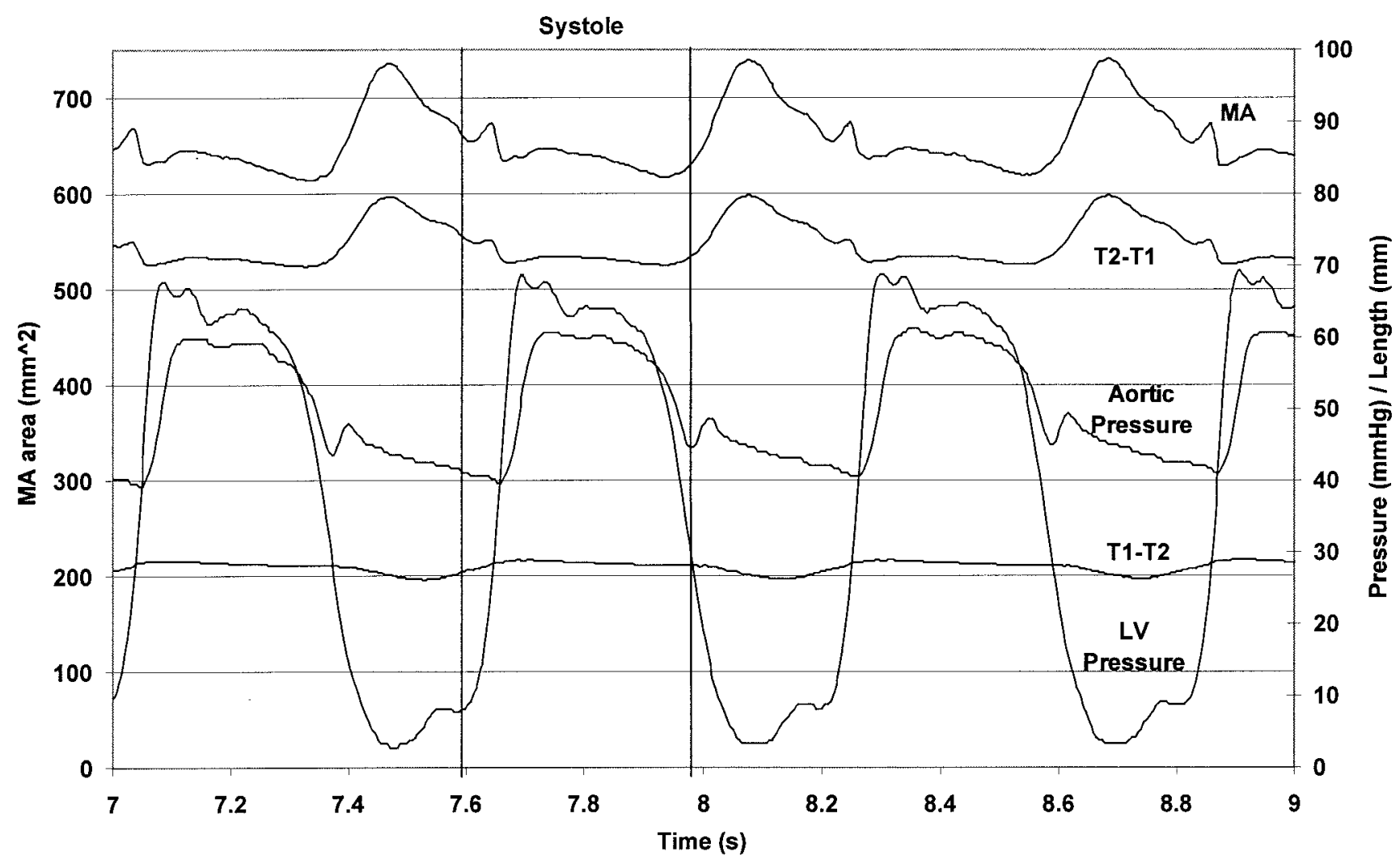

Figure 3. Dynamic changes of the mitral anulus area during the cardiac cycle (MA) and of the anterior (T1-T2) and posterior (T2-P2-PM-P1-T1) anulus lengths (sheep 7).

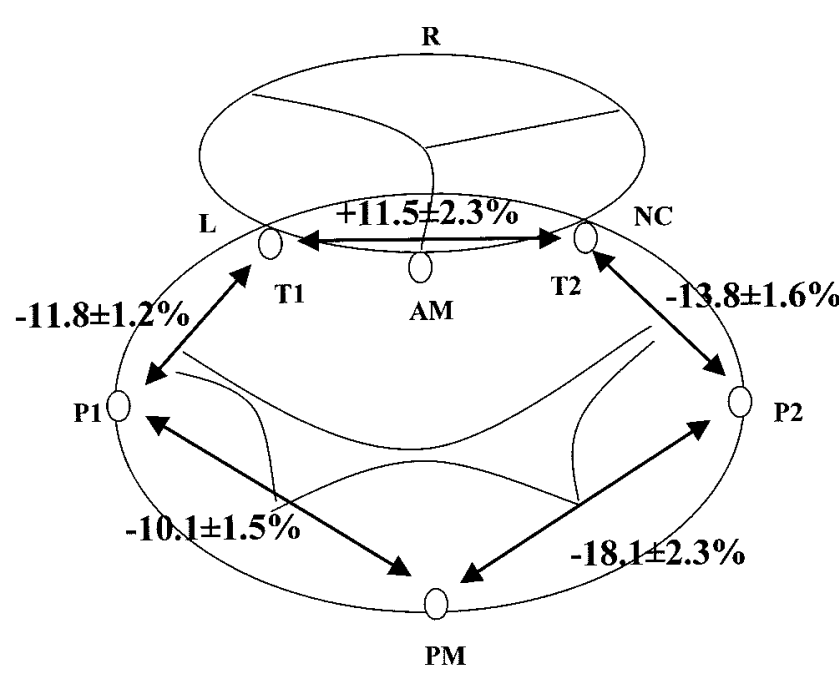

Figure 4. Diagram of the heterogeneous mitral anulus motion from early diastole to end-systole. Note that all posterior segments of the mitral anulus contract, whereas the intertrigonal distance (T1-T2) expands. $R, L$, and NC, Base of the right, left, and noncoronary sinuses of Valsalva; $T 1$ and $T 2$, left and right trigones; $A M$, midpoint between $\mathrm{T} 1$ and $\mathrm{T} 2 ; \boldsymbol{P M}$, midpoint of posterior anulus; $\boldsymbol{P 1}$ and $\boldsymbol{P} 2$, widest mitral diameter. nature of the intertrigonal area. However, the explanation became apparent when we analyzed the movements of the crystal placed at the base of the aortic curtain midway between the 2 trigonal crystals (AM). The angle formed by this point (AM) as its apex and both trigones as sides (T1 and T2) showed that it decreased during systole by $-9 \%$, which illustrated the posterior bulging of intertrigonal portion (AM) toward the mitral orifice. These findings corroborated previous descriptions of systolic annular folding related to the posterior displacement of the anterior mitral anulus toward the left atrium..$^{9,11,12}$

All these data show that the aortic and mitral valves are part of a single structure. Both valves share a common area (the aortic curtain) but also function in synchrony, facilitating their function during the cardiac cycle. During early diastole, the mitral orifice becomes larger because of the very significant expansion of its anteroposterior and transverse diameters. The anteroposterior enlargement is primarily caused by the expansion of the posterior anulus but also by the displacement of the intertrigonal area toward the aortic orifice (reducing its overall length; Figure 5, a). During systole, the aortic orifice expands, including a dis- 

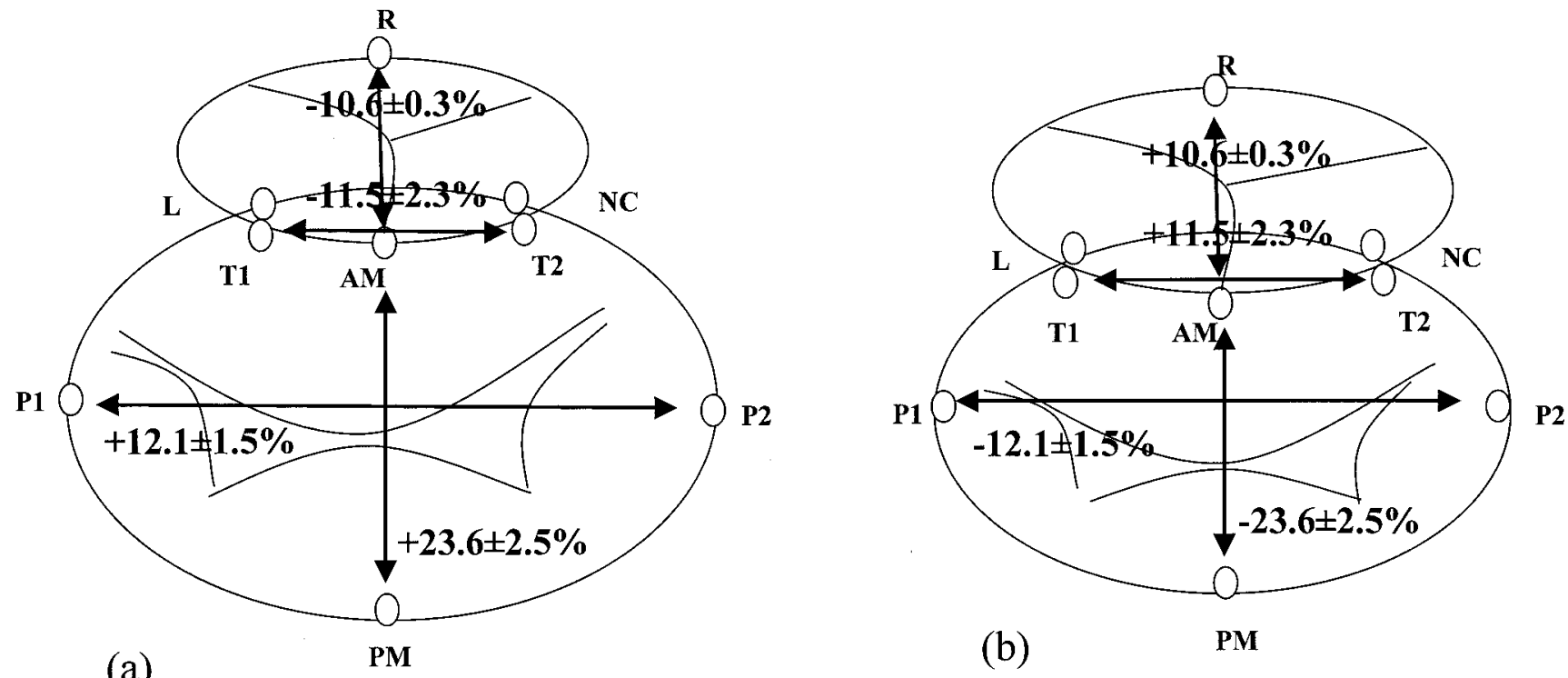

Figure 5. Diagram of the aortic and mitral annular changes during early diastole (a) and late diastole and systole (b). The figures show the increase (+) and reduction (-) in the different aortic and mitral diameters. $R, L$, and $N C$, Base of the right, left, and noncoronary sinuses of Valsalva; $T 1$ and $T 2$, left and right trigones; $A M$, midpoint between T1 and T2; $P M$, midpoint of posterior anulus; $P 1$ and $P 2$, widest mitral diameter.

TABLE 2. Phase-related changes in distance between the left and noncoronary sinus crystals and trigone crystals

\begin{tabular}{lccccccc}
\hline & $\begin{array}{c}\text { Isovolumic } \\
\text { contraction }\end{array}$ & $\begin{array}{c}\text { Ejection } \\
\text { (first third) }\end{array}$ & $\begin{array}{c}\text { Ejection } \\
\text { (last two thirds) }\end{array}$ & $\begin{array}{c}\text { Isovolumic } \\
\text { relaxation }\end{array}$ & $\begin{array}{c}\text { Motal } \\
\text { Mid-diastole }\end{array}$ & $\begin{array}{c}\text { End-diastole } \\
\text { expansion }\end{array}$ \\
\hline Basal L-NC (\%) & $+37.8 \pm 8.5$ & $+44.5 \pm 5.0$ & $-37.7 \pm 7.6$ & $-40.5 \pm 13.1$ & $-37.5 \pm 3.8$ & $+33.4 \pm 5.5$ & $12.9 \pm 2.0$ \\
Basal L-NC (mm) & $17.67 \pm 1.25$ & $18.79 \pm 1.10$ & $18.06 \pm 1.12$ & $16.87 \pm 1.13$ & $16.24 \pm 1.24$ & $16.82 \pm 1.27$ & $1.97 \pm 0.13$ \\
$P$ value & .003 & .012 & .002 & .005 & .002 & .005 & .002 \\
T1-T2 (\%) & $+52.4 \pm 6.8$ & $+16.2 \pm 4.4$ & $-47.9 \pm 6.4$ & $-31.4 \pm 4.4$ & $-19.4 \pm 4.6$ & $+30.1 \pm 3.1$ & $11.5 \pm 2.3$ \\
T1-T2 (mm) & $26.16 \pm 1.03$ & $26.38 \pm 1.09$ & $25.42 \pm 1.12$ & $24.53 \pm 1.29$ & $23.92 \pm 1.49$ & $24.62 \pm 1.40$ & $2.46 \pm 0.12$ \\
$P$ value & .019 & .034 & .010 & .010 & .031 & .006 & .007 \\
\hline
\end{tabular}

Data are displayed as the percentage of length changes for each phase of the cardiac cycle relative to the total changes over the entire cycle and as the raw length value measured at the end of each phase of the cardiac cycle. Results are expressed as means \pm 1 SEM. Length changes were tested for significance by using the Student $t$ test for paired observation. The time-related changes of the aortic base distance between the left and noncoronary sinus crystals (Basal L-NC) and the mitral intertrigonal distance (T1-T2) were strongly correlated during each phase of the cardiac cycle (Pearson correlation, $r=0.85$ ).

placement of the intertrigonal space toward the posterior mitral anulus, facilitating ejection (Figure $5, b$ ). The synchronized movements of the mitral and aortic anuli are a complex mechanism designed to facilitate the filling and emptying of the left ventricle.

These findings should have important clinical implications. Mitral or aortic valve replacement with a rigid prosthesis must significantly interfere with the normal movements of the other valve. If the valve is repaired, insertion of a rigid annuloplasty ring that immobilizes not only the posterior mitral anulus but also the aortic curtain must interfere with aortic valve dynamics. It is hoped that these data will stimulate new thinking on the surgical approach to left-side valvular surgery.

\section{Limitations of the Study}

The main limitation of this study is the comparison of the aortic and mitral anulus dynamics with 2 different groups of animals under different hemodynamic conditions at the time of data recording. Although the mean heart rates were different, cardiac output and systemic pressures were similar. The validity of this comparison lies in the fact that the measurements obtained were not related to absolute time (milliseconds) but to the percentage of change in distances and areas related to each phase of the cardiac cycle in each animal. Because the parameters (aortic and LV pressure) used to define the different phases of the cardiac cycle were identical in both groups, we compared the time-related changes of the aortic and mitral anuli within each phase of 
the cardiac cycle. Also, the acute and invasive nature of our model, particularly the deleterious effect of cardiopulmonary bypass and ischemia, might have resulted in an abnormal valve behavior. Furthermore, it can also be argued that the high heart rate present at the time of data acquisition (probably caused by catecholamine release) might alter the aortic or mitral annular motion recorded during the shorter cardiac cycles. No autonomic blockade was used to avoid LV function depression and therefore depressed systolic mitral annular motion. The constant patterns found in all animals and the fact that all geometric changes were related to the cardiac phases support the validity of our findings. The possible source of error caused by the presence of crystals and attached electrodes is inherent to all marker techniques. Although the aortic root electrodes were passed through the aortic wall at each location and therefore outside the aortic lumen, the mitral anulus electrodes traversed the left atrium. Furthermore, variability in the precise location of the crystals must be considered, although, being conscious of this problem, all operations were performed by the same individual. Also, it must be pointed out that our findings in the sheep cannot be totally applicable to human subjects.

We thank Kathleen Billington and Leslie Trail for their effort and support, which were essential to the completion of these experiments.

\section{References}

1. Brewer RJ, Deck JD, Capati B, Nolan SP. The dynamic aortic root: its role in aortic valve function. J Thorac Cardiovasc Surg. 1976;72: 413-7.

2. Thubrikar M, Bosher LP, Nolan SP. The mechanism of opening of the aortic valve. J Thorac Cardiovasc Surg. 1979;77:863-70.

3. Van Renterghem RJ, van Steenhoven AA, Arts T, Reneman RS. Deformation of the dog aortic valve during the cardiac cycle. Eur J Physiol. 1988;412:647-53.

4. Pang DC, Choo SJ, Luo HH, Shomura Y, Daniel S, Nikolic S, et al. Significant increase of aortic root volume and commissural area occurs prior to aortic valve opening. J Heart Valve Dis. 2000;9:9-15.

5. Dagum P, Green GR, Nistal FJ, Daughters GT, Timek TA, Foppiano LE, et al. Deformational dynamics of the aortic root: modes and physiologic determinants. Circulation. 1999;100(Suppl):II-54-62.

6. Lansac E, Lim HS, Shomura Y, Rice NT, Lim KH, Yoe JH, et al. The mechanisms of aortic valve opening and closure [abstract]. J Am Coll Cardiol. 2001;37(suppl A):475A.

7. Tsakiris AG, von Bernuth G, Rastelli GS, Bourgeois MJ, Titus JL, Wood EG. Size and motion of the mitral valve annulus in anesthesized intact dogs. J Appl Physiol. 1971;30:611-8.

8. Ormiston JA, Shah P, Tei C, Wong M. Size and motion of the mitral valve annulus in man. Circulation. 1981;64:113-20.

9. Glasson JR, Komeda M, Daughters GT, Niczyporuk MA, Bolger AF, Ingels $\mathrm{N}$, et al. Three-dimensional regional dynamics of the normal mitral anulus during left ventricular ejection. $J$ Thorac Cardiovasc Surg. 1996;111:574-85.

10. Fawzy HF, Fukamatchi K, Drake M Jr, Vesely I. Three dimensional motion of the mitral valve apparatus [abstract]. Circulation. 1997;96: I-731.
11. Komoda T, Hetzer R, Oellinger J, Siniawski H, Hofmeister J, Hübler M, et al. Mitral annular flexibility. J Card Surg. 1997;12:102-9.

12. Flachskampf FA, Chandra S, Gadipatti A, Levine RA, Weyman AE, Ameling W, et al. Analysis of shape and motion of the mitral annulus in subjects with and without cardiomyopathy by echocardiographic 3-dimensional reconstruction. Am Soc Echocardiogr. 2000;13:277-87.

13. Vesely I, Fawzy HS, Fukamachi K, Drake M Jr. Use of threedimensional sonomicrometry to study the motion of the mitral valve. ASAIO J. 1997;43:M465-9.

14. Gorman JH, Gupta KB, Streicher JT, Gorman RC, Jackson BM, Ratcliffe MB, et al. Dynamic three-dimensional imaging of the mitral valve and the left ventricle by rapid sonomicrometry array localization. J Thorac Cardiovasc Surg. 1996;112:712-26.

15. Kumar N, Kumar M, Duran CMG. A revised terminology for recording surgical findings of the mitral valve. J Heart Valve Dis. 1995;4: $70-5$.

16. Guyton AC, Hall JE, editors. Heart muscle; the heart as a pump. In: Textbook of medical physiology. 9th ed. Philadelphia: WB Saunders; 1995. p. 110-5.

17. Mountcastle VB. Circulation; the heart as a pump. In: Mountcastle VB, editor. Medical physiology. Vol. II. 13th ed. St Louis: Mosby; 1974. p. 892-3.

18. Fung YC. Biomechanics: motion, flow, stress, and growth. New York: Springer-Verlag; 1990. p. 358.

19. Pappas T. Heron's theorem. In: The joy of mathematics. San Carlos (CA): Wide World Publications/Tetra; 1989. p. 62.

20. Glasson JR, Komeda M, Daughters GT, Foppiano LE, Bolger AF, Terrence LT, et al. Most ovine mitral annular three-dimensional size reduction occurs before ventricular systole and is abolished with ventricular pacing. Circulation. 1997;96(Suppl 9):II-115-22.

21. Sutton JP, Ho SY, Anderson RH. The forgotten interleaflet triangles: a review of the surgical anatomy of the aortic valve. Ann Thorac Surg. 1995;59:419-27.

22. Anderson RH, Devine WA, Ho SY, Smith A, McKay R. The myth of the aortic annulus: the anatomy of the subaortic outflow tract. Ann Thorac Surg. 1991;52:640-6.

\section{Discussion}

Dr Edward D. Verrier (Seattle, Wash). I think, clearly, much of your presentation mirrors the intuitive thoughts that we have when we think of the mitral and aortic anuli. I am intrigued by the fact that there is such motion at that intertrigonal distance.

Do your conclusions have an implication in understanding the aortic root; that is, does a stentless prosthesis or a rigid ring have the same effect on those dynamics as, for instance, a flexible or rigid ring on the mitral valve?

Dr Lansac. Thank you for this question. I think it is a very good point. The fact is that the increase in length of the intertrigonal distance is not huge, but approximately $2 \mathrm{~mm}$. It is not very accurate to talk about absolute values because they changed between animals.

The fact that the intertrigonal distance is moving with the aortic valve suggests that if you have a flexible device on the aortic side, it will not interfere with the mitral valve. The expansion of the intertrigonal distance was really clearly related to the expansion of the aortic root to maximize ejection. The expansion of the aortic root that we previously studied showed that the aortic volume was expanding more than $30 \%$, and that each area of the aortic root was expanding by $60 \%$ at end-diastole. Therefore, it is a combined mechanism to either maximize LV filling or to maximize ejection. 